\title{
EL ROL DEL ASESOR \\ EN UN MODELO DE \\ EDUCACIÓN A DISTANCIA
}

Gabriela Martínez

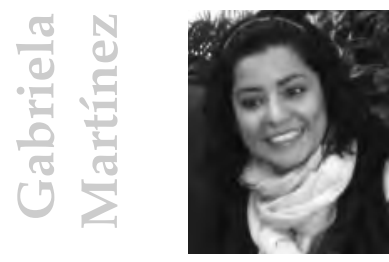

Licenciada en Pedagogía por la Universidad Panamericana, Campus Ciudad de México. Actualmente es Coordinadora Académica del departamento de Universidad Abierta de la Universidad Panamericana.

Correo electrónico:

[gabriela.martinez@up.edu.mx].

\section{RESUMEN}

La educación a distancia cobra auge en la medida en que brinda oportunidades educativas a quienes no pueden o no desean, por diversas razones, recurrir a un sistema escolarizado presencial.

Esta educación no se limita a ir más allá de condiciones espaciotemporales o personales del alumnado. Se trata de una educación con rasgos precisos y fisonomía particular.

El papel del docente aquí es clave para generar eficientes y motivadores ambientes virtuales de aprendizaje.

Palabras clave: educación a distancia; modelo presencial; comunidades interdisciplinarias; comunicación; interacción; retroinformación. 


\section{ABSTRACT}

The education on distance is progressing rapidly insofar it offers educational opportunities to whom are not able or they do not wish, by several different reasons, to appeal to a presence scholastic system.

This education is not limited to go over there of space-time conditions or personals conditions of pupils. It refers to an education with precise features and particular physiognomy.

Here, teacher's paper is crucial to generate efficient and full motivation virtual environments for apprenticeship.

Key words: education on distance; presence model; inter-disciplines communities; communication; interaction; retro-information.

\section{LA EDUCACIÓN A DISTANCIA}

La educación a distancia no es una modalidad nueva en el campo pedagógico; desde hace décadas se han tratado de brindar oportunidades educativas a quienes no tienen la posibilidad de acudir a un aula en un sistema escolarizado o que se encuentran en lugares geográficamente distintos a las instituciones educativas que ofertan los programas de su interés.

Según Peñalver son varios los fenómenos que han catalizado el auge actual de la educación a distancia: la expansión educativa a todos los niveles; el fenómeno de renovación de los conocimientos y las técnicas como resultado del progreso científico; la concepción pedagógica de la «enseñanza individualizada», así como la demanda de estudiantes con distintas necesidades académicas y el propio avance tecnológico de la comunicación e informática ${ }^{1}$.

1 J.L. García Llamas, El aprendizaje adulto en un sistema abierto y a distancia, p. 30-31. 
Además, la educación a distancia como modalidad otorga una respuesta clara a lo establecido por la UNESCO como una realidad educativa del siglo XXI: la educación a lo largo de la vida.

Ahora se trata de que [la educación permanente] ofrezca a todos la posibilidad de recibir educación, y ello con fines múltiples, tanto si se trata de brindar una segunda o tercera ocasión educativa o de satisfacer la sed de conocimientos, de belleza o de superación personal, como de perfeccionar y ampliar los tipos de formación estrictamente vinculados con las exigencias de la vida profesional, comprendidos los de formación práctica².

Esta multiplicación de posibilidades educativas se posibilita y favorece por la educación a distancia, pues no está limitada por condiciones espacio-temporales ni restringida a una edad específica del alumnado. Promueve, también, la creación de nuevas estructuras que faciliten un aprendizaje a lo largo de la vida.

Así, la educación a distancia hoy no solamente favorece la inclusión educativa, a sistemas formales e informales, a personas con diversas situaciones, expectativas e intereses, sino que además forma, por medio de programas de estudio, comunidades interdisciplinarias a partir grupos heterogéneos de individuos.

Se presentan a continuación, de manera no limitativa, algunas de las principales diferencias entre un modelo educativo presencial y uno a distancia; serán estas diferencias las que demanden un rol docente distinto para cada modelo.

2 J. Delors (coord.), La educación encierra un tesoro, p. 121. 
Diferencias entre un modelo educativo presencial y a distancia

\begin{tabular}{|c|c|c|}
\hline & Modelo presencial & Modelo a distancia \\
\hline Alumnos & $\begin{array}{l}\text { Grupos principalmente } \\
\text { homogéneos. } \\
\text { Basta dedicación en } \\
\text { tiempo al estudio. }\end{array}$ & $\begin{array}{l}\text { Grupos principalmente } \\
\text { heterogéneos. } \\
\text { Limitantes de tiempo para } \\
\text { dedicar al estudio. }\end{array}$ \\
\hline Comunicación & $\begin{array}{l}\text { Continua. } \\
\text { Sincrónica. } \\
\text { Cara a cara. }\end{array}$ & $\begin{array}{l}\text { Sincrónica-asincrónica. } \\
\text { Mediatizada. }\end{array}$ \\
\hline Metodología & $\begin{array}{l}\text { Generalmente expositiva- } \\
\text { participativa. }\end{array}$ & Eminentemente participativa. \\
\hline $\begin{array}{l}\text { Recursos } \\
\text { tecnológicos }\end{array}$ & No son indispensables. & Indispensables. \\
\hline $\begin{array}{l}\text { Lugar } \\
\text { Tiempo }\end{array}$ & $\begin{array}{l}\text { Espacio definido. } \\
\text { Horarios fijos previamente } \\
\text { establecidos. }\end{array}$ & $\begin{array}{l}\text { Espacio indefinido. } \\
\text { Flexibilidad de horarios. }\end{array}$ \\
\hline
\end{tabular}

Como resultado de estas características, proponemos una definición de educación a distancia como proceso educativo, centrado en el alumno, que no exige una convergencia espacio-temporal entre profesor y alumno; donde el profesor, además de ser un facilitador y guía para el estudiante, emplea distintas tecnologías de comunicación e información para mediar el proceso de enseñanza-aprendizaje.

La eficiencia de cada modelo posee varios factores a considerar, sin embargo, un factor clave para el éxito de cualquier modelo educativo o diseño instruccional a distancia reside en la creación de verdaderos ambientes de aprendizaje virtuales, lo que representa un auténtico reto en el proceso de enseñanza. 
El docente debe generar distintos medios y modos de relación con sus alumnos para lograr que el ambiente virtual de aprendizaje genere comunidades interdisciplinarias, de manera que el éxito de ese ambiente esté condicionado por la relación entre docente y alumnos, lo mismo que entre pares, así como la cohesión y la sinergia que generen como grupo.

Es indispensable que la intervención del asesor se base en un nuevo rol docente adaptable a las condiciones específicas de esta modalidad educativa.

Este nuevo rol parte de un método distinto al utilizado dentro de un aula, pues no se espera del asesor a distancia una clase magistral o una conferencia: resultaría ineficiente para los alumnos y para el mismo profesor (además de contar con pocas probabilidades de impacto significativo en el aprendizaje de los alumnos). Lo que realmente se busca es que el profesor facilite el auto aprendizaje de los alumnos, es decir, que sea un tutor.

Tal como lo concibe González-Simancas, el tutorial system es una metodología que tiene como objetivo:

[...] enseñar a pensar al estudiante en torno a una parcela del saber propio de una determinada área de conocimiento, que se trabaja en profundidad $^{3}$.

Al concebirse a sí mismo como un tutor, el docente reconocerá su función orientadora hacia los alumnos dentro del proceso de enseñanzaaprendizaje. Él no proporciona directamente la información al grupo, sino que motiva a los alumnos a investigar y estructurar la información para generar sus propias formulaciones e interpretaciones.

Bajo la perspectiva tutorial, el docente replanteará cuidadosamente tres aspectos fundamentales en su nuevo rol dentro de un ambiente virtual, así como en la planeación y ejecución de sus asesorías: comunicación, interacción y retroinformación.

3 J.L. González-Simancas, Principios del tutoring, p. 3. 


\section{Comunicación}

El proceso educativo es, por propia definición, un proceso comunicativo en donde docente y discente establecen un código para enviar y recibir un mensaje específico con la intencionalidad de perfeccionamiento que requiere la acción educativa.

En un ambiente virtual es indispensable replantar, desde la planeación, el proceso de comunicación que se llevará a cabo entre tutor y alumnos, utilizando de la manera más eficiente posible los recursos tecnológicos que faciliten y creen canales nuevos para este fin.

La mejor herramienta para lograrlo es la creación de foros de discusión en que participen los alumnos, el asesor y la propia coordinación académica de la institución, de manera que el proceso comunicativo sea accesible para todos los agentes que intervengan en el curso.

Se recomienda la creación de diversos espacios para los distintos tipos de comunicación que pueden generarse durante el curso. Se diseña así un espacio exclusivo para avisos y notificaciones de carácter administrativo y académico; un espacio libre donde los alumnos expongan sus expectativas e intereses respecto al curso al iniciarlo, así como un espacio para dudas, comentarios y sugerencias sobre los temas estudiados, las lecturas o los materiales empleados.

Independientemente a estos espacios de comunicación, lo más recomendable es considerar un espacio «libre», es decir, un foro común en el cual los alumnos y el tutor, interactúen.

\section{Interacción}

Se plantea aquí una diferencia entre comunicación e interacción, aludiendo a un grado mayor de reciprocidad en la interacción que en el proceso comunicativo. Por definición la interacción es «acción que se ejerce recíprocamente entre dos o más objetos, agentes, fuerzas, funciones, etcétera» (RAE, 2009). 
Esta acción recíproca requiere, por parte del tutor, una verdadera integración a la comunidad de virtual, estableciendo una relación estrecha con cada alumno. Solamente se logrará una auténtica interacción en la medida en que el tutor esté involucrado con el grupo, por lo que se proponen considerar los siguientes factores en la asesoría a distancia:

- Conocer el perfil del grupo: Si el tutor estudia el perfil de su grupo antes de iniciar el curso a distancia, será mucho más fácil para él planear actividades y foros de discusión adaptados a las características de sus alumnos, y podrá también incluir material complementario a los temas. El perfil que debe conocer el tutor, incluye datos como: edad, estudios previos, estudios relacionados con el curso, actividad profesional, actividades recreativas y sociales relacionadas con el curso.

- Compartir las propias expectativas e intereses: Es indispensable conocer las expectativas y los intereses de los alumnos, pero es también importante que los alumnos conozcan las expectativas del tutor respecto al curso, a su desempeño, a los trabajos y las actividades, etcétera. De igual manera, será valioso para establecer la interacción adecuada, el que los alumnos conozcan los intereses del tutor - tanto académicos como personales- para generar una empatía, no únicamente profesional sino personal.

- Compartir su propia experiencia: Para lograr una interacción profunda y una confianza por parte de los alumnos respecto al sistema educativo a distancia, es vital que éstos lleguen a conocer a su propio tutor y sea éste quien les brinde la seguridad necesaria para lograr sus objetivos. Es tarea fácil si el tutor comparte su propia experiencia, dentro los sistemas a distancia, con grupos previos o clases anteriores, respecto a estrategias que a él le han funcionado en la comunicación a distancia, lo mismo que recomendaciones prácticas para el manejo del material o de las herramientas tecnológicas. 


\section{Retroinformación}

Es esencial cuidar la retroinformación en un modelo educativo a distancia, pues será ésta la que motive a los alumnos en su autoaprendizaje y les ayude a alcanzar los objetivos propuestos al inicio del curso. Para que la retroinformación que brinde el tutor sea efectiva, debe cuidar tres aspectos y adaptarlos al ambiente virtual: modo, momento y motivo.

- Modo: Para una retroinformación efectiva en el modo, es necesario utilizar el sándwich de feedback. Se inicia con una apreciación positiva del trabajo realizado para después señalar las equivocaciones y fallas, y sugerir indicaciones de mejora para finalizar con una idea que resalte el esfuerzo del alumno y lo motive. El proceso sigue el patrón positivo, negativo, positivo (por esto es nombrado sándwich).

- Momento: En un sistema de educación a distancia, los tiempos de comunicación e interacción son fundamentales para que los alumnos logren los objetivos de aprendizaje. Es aconsejable responder a cada comunicación de los alumnos (chat, e-mail, entradas en foro...) con menos de 24 horas; así como evaluar trabajos y proporcionar las observaciones en un lapso no mayor a cinco días. De esta manera, los alumnos perciben el compromiso del tutor respecto a su labor docente.

- Motivo: El motivo de la retroinformación deberá ser siempre ayudar al estudiante, interesarse para que logre los objetivos propuestos en el curso y fomente su desarrollo profesional y personal.

La eficiencia de cualquier modelo educativo a distancia depende, en gran medida, de la eficiencia de sus tutores para generar canales de comunicación, ambientes de aprendizaje virtuales y comunidades interdisciplinarias de conocimiento. Tanto el modelo educativo como el diseño instruccional del programa son importantes, sin embargo, el eje central será el papel que sustente el asesor y su manera de relacionarse con los alumnos. 


\section{BIBLIOGRAFÍA}

AMADOR BAUTISTA, R. (coord.), Educación y tecnologías de la información y la comunicación. Paradigmas teóricos de la investigación, México, Universidad Nacional Autónoma de México, Instituto de Investigaciones sobre la Universidad y la Educación, y Plaza Valdés Editores, 2008.

CABERO ALMENARA, J., Nuevas tecnologías aplicadas a la educación, Madrid, McGraw-Hill, 2007.

CARRIÓN CARRANZA, C. (coord.), Educación para una sociedad del conocimiento, México, Trillas-UNESCO, 2008.

CAVANAUGH, C. (ed.), Development and management of virtual schools: issues and trends, EUA, Information Science Publications, 2004.

CROVI DRUETTA, D.M., Comunicación educativa y mediaciones tecnológicas: hacia nuevos ambientes de aprendizaje, México, Instituto Latinoamericano de Comunicación Educativa, 2007.

DELORS, J. (coord.), La educación encierra un tesoro, México, UNESCO Ediciones, 1996.

GARCÍA LLAMAS, J.L., El aprendizaje adulto en un sistema abierto y a distancia, Madrid, Narcea, 1986.

GONZÁLEZ-SIMANCAS, J.L., Principios del tutoring, Pamplona, Universidad de Navarra, 1992.

LEVY, Y., Assessing the value of e-learning systems, EUA,

Information Science Publications, 2006.

REAL ACADEMIA ESPAÑOLA, Diccionario de la lengua española, Fecha de consulta: 21-05-09, en:

[http:/ / buscon.rae.es/draeI/SrvltConsulta?TIPO_BUS=3\&LEMA=interaccion]. 